\title{
Hubungan Stres Kerja, Konflik Dan Lingkungan Kerja Fisik Terhadap Prestasi Karyawan PT. Telesindo Shop Batam
}

\author{
Toto Cahya Praja, Firmansyah Kusasi, Iranita
}

Fakultas Ekonomi Universitas Maritim Raja Ali Haji, Tanjungpinang, Kepulauan Riau, Indonesia

\begin{abstract}
ABSTRAK : Di dunia bisnis saat ini berkembang pesat ini bisa dilihat persaingan antar perusahaan. PT. Telesindo Shop sebagai dealer resmi Telkomsel selalu meningkatkan kualitas dan kuantitas perusahaan. Dalam penelitian ini peneliti tertarik untuk melakukan penelitian di PT. Telesindo Shop Batam yang bertujuan untuk mengetahui apakah ada hubungan stres kerja, konflik kerja dan lingkungan kerja fisik terhadap kinerja karyawan. Penelitian ini menggunakan metode kuantitatif dengan teknik pengumpulan data melalui kuesioner. Sampel dalam penelitian ini berjumlah 30 orang menggunakan metode sampel penuh. Hasil penelitian menyimpulkan bahwa stres kerja, konflik kerja dan lingkungan fisik secara parsial memiliki pengaruh positif dan signifikan terhadap kinerja karyawan. Sementara itu, secara simultan stres kerja, konflik kerja dan lingkungan kerja secara bersama-sama memiliki pengaruh terhadap kinerja karyawan pada PT. Telesindo Shop Batam. Variabel yang paling dominan adalah lingkungan kerja. Hasil penelitian ini menyiratkan bahwa stres kerja, konflik kerja dan lingkungan kerja adalah hal-hal yang perlu diperhatikan untuk meningkatkan kinerja karyawan agar lebih baik untuk merealisasikan tujuan perusahaan.
\end{abstract}

Kata kunci: Stres Kerja, Konflik Kerja, Lingkungan Kerja Fisik dan Kinerja Karyawan.

ABSTRACT : In the business world today is growing rapidly this can be seen competition between companies.PT. Telesindo Shop as the official dealer of Telkomsel always improves the quality and quantity of the company.In this study reasearchers are interest in conducting research at PT. Telesindo Shop chapter Batam which aims to determine whether there is influence or how much influence the work stress, work conflict and physical work environment on employee performance. This study uses quantitative methods with data collection techniques through quentionnairies. Sample in this study were 30 people using full sample methods.The results of the study concluded that work stress, work conflict and physical environment partially have a positive and significant influence on employee performance. Meanwhile, simultaneously work stress, work conflict and work environment together have influences on employee performance at PT. Telesindo Shop chapter Batam. The most dominant variable is the physical environment. The results of this study imply that work stress, conflict and environment are things that need to be considered to improve employee performance to be better for the realization of company goals.

Keywords: Work Stress, Conflict, Working Environment and Perfomance.

Email Address : totocahyapraja@gmail.com 


\section{PENDAHULUAN}

Sumber Daya Manusia adalah ujung tombak yang akan menentukan keberhasilan kegiatan suatu perusahaan. Di dunia bisnis pada masa ini yang sedang berkembang pesat dapat dilihat dari persaingan antar perusahaan, perkembangan ilmu pengetahuan dan teknologi semakin canggih yang mengakibatkan tuntunan yang lebih bagi pola kehidupan karyawan. Perubahan tersebut adalah faktor yang mempengaruhi karyawan untuk lebih meningkatkan prestasi kerja mereka. PT. Telesindo Shop sebagai dealer resmi Telkomsel dan mengageni pemasaran voucer pulsa isi ulang produk operator seluler Telkomsel diseluruh nusantara. Perusahaan ini berhasil mencatatakan omset fantastis, yaitu 4,5 triliun dalam 5 tahun terakhir. Saat ini PT. Telesindo Shop memiliki 400 gerai dan 300 subdealer di seluruh Indonesia. Pada tahun ini, perusahaan rencananya akan menambah lagi sekirar 30.000 reseller aktif dan akan menjadi 200.000 sampai akhir tahun ini. Serta akan menabah 100 gerai sampai dengan akhir tahun depan. Perusahaan ini menargetkan penjualan pada tahun 2018 sebesar 6 triliun di seluruh Indonesia.

Dari data di atas dapat disimpulkan bahwasannya PT. Telesindo Shop bisa mencapai tujuan tersebut salah satunya dengan meningkatkan kualitas dan kuantitas sumber daya yang dimiliki. Ada beberapa masalah yang berkaitan dengan sumber daya manusia di perusahaan ini, salah satunya adalah masalah prestasi kerja. Demgan kondisi perusahaan seperti ini, maka prestasi kerja sangat dipengaruhi oleh stres kerja, konflik kerja serta lingkungan kerja fisik.

\section{Tujuan dan Manfaat Penelitian}

Dalam penelitian ini bertujuan untuk melakukan penelitian di PT. Telesindo Shop cabang Batam yang bertujuan untuk mengetahui adakah pengaruh ataupun seberapa besar pengaruh stres kerja, konflik kerja dan lingkungan kerja fisik terhadap prestasi kerja karyawan pada PT. Telesindo Shop cabang Batam.

Untuk mendapatkan bukti empiris apakah stres kerja, konflik kerja dan lingkungan kerja fisik mempunyai pengaruh positif terhadap prestasi kerja karyawan, maka diperlukan beberapa hipotesis yang dapat digunakan dalam penelitian ini. Hipotesis dalam penelitian ini adalah diduga secara parsial stres kerja, konflik kerja dan lingkungan kerja fisik berpengaruh positif dan signifikan terhadap prestasi kerja kemudian diduga secara simultan stres kerja, konflik kerja dan lingkungan kerja fisik berpengaruh signifikan terhadap prestasi kerja.

\section{Variabel Penelitian}

Berdasarkan permasalahan yang dikemukakan, penelitian ini menggunakan 3 variable sebagai independent variable dan 1 dependent variable. Independent variable (variabel bebas) dalam penelitian ini meliputi stres kerja (X1), konflik kerja (X2) dan lingkungan kerja fisik (X3) sedangkan dependent variable (variabel terikat) dalam penelitian ini adalah prestasi kerja yang disimbolkan (Y).

Adapun definisi variabel stres kerja adalah perasaan tertekan yang dialami karyawan dalam menghadapi pekerjaan (Mangkunegara, 2011). Konflik kerja adalah suatu pertentangan yang terjadi antara apa yang diharapkan oleh seseorang terhadap dirinya, orang lain organisasi degan kenyataan apa yang diharapkan (Mangkunegara, 2011:155).

Lingkungan kerja fisik adalah semua keadaan berbentuk fisik yang terdapat disekitar tempat kerja yang dapat mempengaruhi karyawan baik secara langsung maupun tidak langsung (Sedarmayanti, 2011:21). Prestasi kerja adalah ungkapan kemampuan yang didasari oleh pengetahuan, sikap, keterampilan dan motivasi dalam menghasilkan sesuatu (Handoko, 2012:19).

\section{Jenis dan Sumber Data}


Jenis data yang digunakan dalam penelitian ini adalah penelitian kuantitatif, data yang berupa angka-angka yang dapat dianalisis dan menghasilkan jawaban- jawaban atas pertanyaan dari permasalahan. Sumber data yang digunakan adalah data primer, data yang diperoleh dan diolah sendiri oleh peneliti yang belum pernah diolah oleh pihak lain melalui hasil kuesioner dan observasi tentang lingkungan kerja fisik dan data yang di berikan oleh manajemen perusahaan.

\section{Analisis Regresi Linier Berganda}

Pengujian hipotesis yang dilakukan dalam penelitian ini dilakukan dengan metode regresi linier yang digunakan untuk memprediksi seberapa jauh perubahan nilai variabel dependen, bila variabel independen dimanipulasi atau dirubah-rubah atau dinaikturunkan (Sujarweni, 2014:149).

Rumus linier berganda:

$\mathrm{Y}=\mathrm{a}+\mathrm{b} 1 \mathrm{X} 1+\mathrm{b} 2 \mathrm{X} 2+\mathrm{b} 3 \mathrm{X} 3+\mathrm{e}$

Keterangan:

$\mathrm{Y} \quad=$ Prestasi Kerja

a $\quad=$ Constanta

$\mathrm{Bi} \quad=$ Keofisien Regresi ke-i

$\mathrm{X} 1=$ Variabel Stres Kerja

$\mathrm{X} 2=$ Variabel Konflik Kerja

X3 = Variabel Lingkungan Kerja Fisik

e $\quad=$ Error distribance

\section{Hasil Analisis Regresi Linier Berganda}

Tabel 1. Hasil Pengujian Regresi Linier Berganda

\begin{tabular}{|c|r|r|r|r|r|}
\hline & \multicolumn{2}{|r|}{$\begin{array}{r}\text { Unstandardize } \\
\text { d Coefficients }\end{array}$} & & \\
\hline Model & B & Std. Error & $\begin{array}{c}\text { Standardized } \\
\text { Coefficients } \\
\text { Beta }\end{array}$ & T & Sig \\
\hline (Constant) & 2.316 & 3.372 & & .687 & .498 \\
\hline STRES_KERJA & .442 & .057 & .389 & 7.729 & .000 \\
\hline KONFLIK_KERJA & .265 & .114 & .195 & 2.323 & .028 \\
\hline LINGKUNGAN_KERJA_FISIK & .817 & .103 & .661 & 7.934 & .000 \\
\hline
\end{tabular}

a. Dependent Variable: PRESTASI_KERJA

Sumber: Output Data Olahan

\section{Hasil Pengujian F (Uji Simultan)}

Tabel 2. Hasil Pengujian F (Uji Simultan)

\begin{tabular}{|c|c|c|c|c|c|c|}
\hline \multicolumn{2}{|c|}{ ANOVA $^{|c|}$} & Sig. \\
\hline \multirow{2}{*}{ Model } & $\begin{array}{c}\text { Sum of } \\
\text { Squares }\end{array}$ & Df & Mean Square & F & \\
\hline & Regression & 768.698 & 3 & 256.233 & 127.459 & $.000^{\mathrm{b}}$ \\
\cline { 2 - 7 } & Residual & 52.268 & 26 & 2.010 & & \\
\cline { 2 - 8 } & Total & 820.967 & 29 & & & \\
\hline
\end{tabular}

a. Dependent Variable: PRESTASI_KERJA

a. Predictors: (Constant), LINGKUNGAN_KERJA_FISIK, STRES_KERJA,

KONFLIK_KERJA (Sumber: Output Data Olahan) 
Tabel 3. Hasil Pengujian Koefisien Determinasi (R2)

\begin{tabular}{|c|r|r|r|r|}
\hline Model & $\mathbf{R}$ & $\begin{array}{c}\mathbf{R} \\
\text { Square }\end{array}$ & $\begin{array}{r}\text { Adjusted } \\
\text { R Square }\end{array}$ & $\begin{array}{c}\text { Std. Error of the } \\
\text { Estimate }\end{array}$ \\
\hline 1 & $.968^{\mathrm{a}}$ & .936 & .929 & 1.418 \\
\hline
\end{tabular}

a. Predictors: (Constant), LINGKUNGAN_KERJA_FISIK, STRES_KERJA, KONFLIK_KERJA

\section{b. Dependent Variable: PRESTASI_KERJA \\ Sumber: Output Data Olahan}

Dari tabel diatas menunjukkan bahwa persentase pengaruh variabel independen yaitu stres kerja, konflik kerja dan lingkungan kerja fisik terhadap variabel dependen yaitu prestasi kerja sebesar $92,9 \%$. Sedangkan sisanya $7,1 \%$ adalah dipengaruhi oleh variabel lain yang tidak dimasukkan dalam model penelitian ini.

\section{PEMBAHASAN}

\section{Pengaruh Stres Kerja (X1) terhadap Prestasi Kerja (Y)}

Analisis melalui nilai koefisien regresi berganda. Koefisien regresi b1X1 sebesar 0,442 yang memiliki arti bahwa setiap penurunan Stres Kerja (X1) sebesar 1 poin dapat meningkatkan Prestasi Kerja karyawan sebesar 2,316 poin. Dilihat dari pengujian hipotesis secara parsial (Uji t) diperoleh nilai sig. $\mathrm{t}<0,05(0,000<0,05)$ dan thitung $>$ ttabel $(7,729>1,70562)$ atau $\mathrm{H} 0$ ditolak dan $\mathrm{H} 1$ diterima. Sehingga dapat disimpulkan bahwa stres kerja berpengaruh positif dan signifikan secara parsial terhadap prestasi kerja.

\section{Pengaruh Konflik Kerja (X2) terhadap Prestasi Kerja (Y)}

Analisis melalui nilai koefisien regresi berganda. Koefisien regresi b1X2 sebesar 0,265 yang memiliki arti bahwa setiap penurunan Konflik Kerja (X2) sebesar 1 poin dapat meningkatkan Prestasi Kerja karyawan sebesar 2,316 poin. Dilihat dari pengujian hipotesis secara parsial (Uji t) diperoleh nilai sig. $\mathrm{t}<0,05(0,028<0,05)$ dan thitung $>$ ttabel $(2,232>1,70562)$ atau $\mathrm{H} 0$ ditolak dan $\mathrm{H} 1$ diterima. Sehingga dapat disimpulkan bahwa konflik kerja berpengaruh positif dan signifikan secara parsial terhadap prestasi kerja.

\section{Pengaruh Lingkungan Kerja Fisik (X3) terhadap Prestasi Kerja (Y)}

Analisis melalui nilai koefisien regresi berganda. Koefisien regresi b1X3 sebesar 0,0,817 yang memiliki arti bahwa setiap penurunan Lingkungan Kerja Fisik (X3) sebesar 1 poin dapat meningkatkan Prestasi Kerja karyawan sebesar 2,316 poin. Dilihat dari pengujian hipotesis secara parsial (Uji t) diperoleh nilai sig. $\mathrm{t}<0,05(0,000<0,05)$ dan thitung > ttabel $(7,934>1,70562)$ atau $\mathrm{H} 0$ ditolak dan $\mathrm{H} 1$ diterima. Sehingga dapat disimpulkan bahwa lingkungan kerja fisik berpengaruh positif dan signifikan secara parsial terhadap prestasi kerja.

\section{Pengaruh Stres Kerja (X1), Konflik Kerja (X2), Lingkungan Kerja Fisik (X3) terhadap Prestasi Kerja (Y)}

Hasil uji $F$ (siumultan) diperoleh signifikasi $\mathrm{F}<0,05(0,000<0,05)$ dan Fhitung $>$ Ftabel $(127,459>2,92)$ atau berarti HO ditolak dan $\mathrm{H} 1$ diterima, hal ini menunjukkan bahwa stres kerja, konflik kerja dan lingkungan kerja fisik berpengaruh secara simultan dan signifikan terhadap prestasi kerja.

\section{KESIMPULAN}

Dari hasil analisis dan pembahasan di atas dapat disimpulkan bahwa secara parsial maupun secara simultan Stres Kerja (X1), Konflik Kerja (X2), dan Lingkungan Kerja Fisik (X3) berpengaruh positif dan signifikan 
@Program Studi Manajemen

FE Universitas Maritim Raja Ali Haji

terhadap Prestasi Kerja Karyawan (Y) pada PT. Telesindo Shop cabang Batam.

\section{DAFTAR PUSTAKA}

Handoko, T. H. (2012). Manajemen Personalia dan Sumber Daya Manusia. Yogyakarta: BPFE.

Mangkunegara, A. A. (2011). Manajemen Sumber Daya Manusia Perusahaan. Bandung: Remaja Rosdakarya.

Sedarmayanti. (2011). Manajemen Sumber Daya Manusia. Reformasi Birokrasi dan Manajemen Pegawai Negeri Sipil, cetakan kelima. Bandung: Aditama.

Sugiyono. (2017). Metode Penelitian Bisnis: Pendekatan Kuantitatif, Kualitatif, Kombinasi dan $R \quad \& \quad D$. Bandung: Alfabeta.

Sujarweni, V. W. (2014). Kupas Tuntas Penelitian Akuntansi dengan SPSS. Yogyakarta: Pustaka Baru Press. 